\title{
Pharmacotherapy for vertigo: a current perspective
}

\author{
Santosh Kumar Swain*
}

Department of Otorhinolaryngology, IMS and SUM Hospital, Siksha "O" Anusandhan University, Kalinganagar, Bhubaneswar, Odisha, India

Received: 19 April 2020

Revised: 14 May 2020

Accepted: 15 May 2020

\section{*Correspondence:}

Dr. Santosh Kumar Swain,

E-mail: santoshvoltaire@yahoo.co.in

Copyright: (c) the author(s), publisher and licensee Medip Academy. This is an open-access article distributed under the terms of the Creative Commons Attribution Non-Commercial License, which permits unrestricted non-commercial use, distribution, and reproduction in any medium, provided the original work is properly cited.

\begin{abstract}
Vertigo is a symptom often encountered in routine clinical practice. Pharmacotherapy plays a vital role for treating the vertigo. Vestibular sedatives and drugs controlling nausea and vomiting constitute the important part of the pharmacotherapy for vertigo. Although there are several drugs available for controlling the vertigo, there are no definitive and universally accepted drugs available for treatment of vertigo. On the basis of the etiology, drugs with specific mechanism of action may be used to control this disabling symptom. Symptomatic treatment is often priority by many clinicians during the treatment of the vertigo. The pharmacological treatment of the vertigo is often decided after correct etiological evaluation of the symptom. Common drugs which are beneficial for treating vertigo are anticholinergics, antihistamines, benzodiazepines, calcium channel blockers and dopamine receptor antagonists. This review article exclusively focuses on pharmacotherapy of vertigo.
\end{abstract}

Keywords: Pharmacotherapy, Vertigo, Cinnarizine, Beta-histine, Dizziness

\section{INTRODUCTION}

Vertigo is a common complaint by the patients in day to day clinical practice. It reflects a variety of diseases which involve the peripheral and/or central vestibular disorders. Vertigo is the hallucination of rotational or spinning motion. It occurs due to dysfunction of the vestibular symptom. In acute onset of the vertigo, patient presents with dizziness, nausea and vomiting whereas dizziness and/or disequilibrium may be the symptom in chronic cases. ${ }^{1}$ The enigma and difficulty for treating the vertigo is due to the fact that this is not a disease but a symptom. The treatment of the vertigo includes drug therapy, physical therapy, psychotherapeutic measures and rarely surgical intervention. Drugs play a crucial role in the management of the vertigo. Vestibular suppressants and medications for controlling nausea and vomiting constitute the mainstay of the treatment. ${ }^{2}$ Clinicians should understand the pathophysiology of the vertigo or vestibular system for effective treatment of the vertigo with drugs. The aim of this review article is to discuss about pharmacological options available for treatment of the vertigo along with its recent advances.

\section{METHODS OF LITERATURE SEARCH}

Research articles regarding pharmacotherapy for vertigo were searched through a multiple systemic approach. First, we conducted an online search of the Scopus, PubMed, Cochrane database, Medline database and Google Scholar with the pharmacotherapy for vertigo. The abstracts of the published articles were identified by this search method and other articles identified manually from citations. The research terms used for literature search included pharmacotherapy of the vertigo, cinnarizine, beta-histine, treatment of the vertigo. This manuscript reviews the details of pharmacotherapy for vertigo patients along with certain important drugs for 
Meniere's disease, vestibular neuritis and migrainous vertigo. This review article presents a baseline from where further prospective trials for pharmacotherapy for vertigo could be designed and helps as a spur for further research in the role of different drugs for treating the vertigo.

\section{EPIDEMIOLOGY}

Approximately 5-7\% of patients attending to the general practitioners suffer from vertigo and balance disorders. ${ }^{3}$ Around $10-12 \%$ of the patients attending to outpatient department of the otorhinolaryngology are patients with symptoms of the vertigo. ${ }^{3}$ Vertigo may be found in all age groups; however it is more with increasing age of the patient. After age of the 65 years, vertigo constitutes third most common cause of symptoms for attending the clinician. $^{4,5}$

\section{AIM OF THE PHARMACOTHERAPY}

The aim of the pharmacotherapy in managing vertigo includes faster resolution of the symptoms to restore normalcy and prevent recurrence. It should also control nausea, vomiting and anxiety along with treatment of the vertigo. For successful outcome, clinician should first do correct diagnosis and then appropriate selection of the drug for its treatment. ${ }^{6}$ Before starting the treatment for vertigo, patient should be informed about the prognosis of vertigo as it often takes the natural course as peripheral vestibular function improves or central vestibular compensation and majority of the vertigo can be successfully treated by drugs and physiotherapy. ${ }^{7}$

\section{MECHANISM OF DRUG ACTIONS IN VERTIGO}

The vestibular system is one of the important sensory components responsible for balance of the body whereas other being vision and somatosensory system. The vestibular system consists of the labyrinth and it consists of three semicircular canals, saccule and utricle. The angular and linear accelerations are originated in the semicircular canals and otolithic apparatus which provides a sense of head position in the space. The neural output of the labyrinthine end organs conveyed to the vestibular nucleus at the brain stem through $8^{\text {th }}$ cranial nerve. The neural projections further go to the $3^{\text {rd }}, 4^{\text {th }}$ and $6^{\text {th }}$ cranial nerves as well as cerebellum, cerebral cortex and spinal cords. There are several neurotransmitters associated with vestibular transmission named as per cholinergic, glutaminergic and monoaminergic synapses. These are actively found in peripheral vestibular central circuits. The neurotransmitters influence the three-neuron arc among vestibular hair cells, oculomotor nuclei which drives the vestibule-ocular reflex. ${ }^{8}$

Glutamate is an important neurotransmitter act via $\mathrm{N}$ methyl-D-aspartate (NMDA) receptors in the nerve fibers of the vestibular branch of the $8^{\text {th }}$ cranial nerve. M2 cholinergic receptors are also associated with vertigo.
Gamma-aminobutyric acid (GABA) is a neurotransmitter inhibitory in nature seen in vestibular nerve causing activation of the GABA-A and GABA-B receptors. ${ }^{9}$ Histamine acts on the $\mathrm{H} 1$ and $\mathrm{H} 2$ receptors found pre and post synpatically of the vestibular cells and alter the vestibular response. Dopamine and nor-adrenaline modulate the vestibular system. Adrenocorticotropic hormone (ACTH) has been documented to enhance the vestibular compensation. ${ }^{10}$

\section{PHARMACOTHERAPY IN VERTIGO}

Vestibular sedatives or vestibular suppressants are the mainstay of treatment for patients with vertigo. These drugs help to reduce the asymmetry of the vestibular tones between the two labyrinths and so reduce the vertigo. ${ }^{11}$ Common antivertigo drugs include anticholinergic, antihistaminic, antidopaminergic and benzodiazepines. Frequently used antivertigo drugs are given in (Table 1).

\section{Anticholinergics}

These drugs act on the muscarinic receptors and increase motion tolerance. The anticholinergics those are acting centrally, useful for treatment of the vertigo. Scopolamine is a highly effective agent used to prevent the vertigo by acting on the M3 and M5 receptors. ${ }^{12}$ Anticholinergics have side effects like dilated pupils, dry mouth, decreased alertness, sedation and impaired attention. Long term use of scopolamine as a transdermal patch can lead addiction. The selective anticholinergic for acting on vestibular specific muscarinic receptors are developed, one such is zamifenacin. $^{13}$

\section{Antihistamines}

The H1 receptor blockers are often prescribed medications for vertigo. These antihistamines include cyclizine, diphenhydramine, dimenhydrinate, meclizine and promethazine. ${ }^{14}$

Meclizine is considered as a long acting drug prescribed among all antihistamines. These drugs have lesser side effects than anticholinergic drugs. Few antihistamines have side effects and these side effects are similar to anticholinergics, as the anti-vertigo effect is usually by their anticholinergic properties. ${ }^{12}$

Meclizine is effectively controlling symptoms of the motion sickness like nausea, vomiting and vertigo. It has also anticholinergic effect. It suppresses the labyrinthine stimulation. The recommended dose of the meclizine is 25 to $50 \mathrm{mg}$ orally, taken one hour before the travel. This drug may be repeated every 24 hours as per requirement.

Cyclizine is a piperazine derivative and has anti-motion sickness effect like dimenhydrinate. It has less sedative effect. $^{15}$ 
Table 1: Frequently used anti-vertigo drugs in clinical practice.

\begin{tabular}{|c|c|c|c|c|}
\hline Drugs & Mechanism of action & Dose & Used in & Side effects \\
\hline Cinnarizine & $\begin{array}{l}\text { Selective calcium channel blocker } \\
\text { and it acts primarily on the peripheral } \\
\text { vestibular labyrinth by interfering } \\
\text { local calcium ion flux }\end{array}$ & $\begin{array}{l}75 \mathrm{mg} \text { per } \\
\text { day }\end{array}$ & $\begin{array}{l}\text { Peripheral } \\
\text { causes of } \\
\text { vertigo }\end{array}$ & $\begin{array}{l}\text { Sedation, weight gain, } \\
\text { pedal edema, } \\
\text { extrapyramidal disorders }\end{array}$ \\
\hline $\begin{array}{l}\text { Cinnarizine and } \\
\text { dimenhydrinate }\end{array}$ & $\begin{array}{l}\text { Cinnarizine is calcium channel } \\
\text { blocker. Dimenhydrinate regulates } \\
\text { vestibular nuclei and adjacent } \\
\text { vegetative nuclei and adjacent } \\
\text { vegetative centers in the brainstem. } \\
\text { Dimenhydrinate enhances the actions } \\
\text { of cinnarizine }\end{array}$ & $\begin{array}{l}\text { Cinnarizine } \\
20 \text { mg and } \\
\text { Dimenhydri } \\
\text { nate } 40 \\
\text { mg/day }\end{array}$ & $\begin{array}{l}\text { Vertigo and } \\
\text { motion } \\
\text { sickness }\end{array}$ & $\begin{array}{l}\text { Affect the occupation } \\
\text { and } \\
\text { cognition extrapyramidal } \\
\text { side effects, high } \\
\text { somnolence }\end{array}$ \\
\hline Prochlorperazine & $\begin{array}{l}\text { A potent neuroleptic, it acts as D2 } \\
\text { blocker in chemoreceptor trigger zone } \\
\text { (CTZ) and has anticholinergic effects } \\
\text { also }\end{array}$ & $\begin{array}{l}10-15 \mathrm{mg} \\
\text { per day }\end{array}$ & $\begin{array}{l}\text { Acute } \\
\text { vertigo }\end{array}$ & $\begin{array}{l}\text { Drowsiness, dizziness } \\
\text { and } \\
\text { dry mouth }\end{array}$ \\
\hline Beta-histine & $\begin{array}{l}\text { It is a histamine analogue which } \\
\text { stimulates } \mathrm{H} 1 \text { and } \mathrm{H} 2 \text { receptors in } \\
\text { vestibular nuclei and brain stem }\end{array}$ & $\begin{array}{l}48 \mathrm{mg} \text { per } \\
\text { day }\end{array}$ & Vertigo & $\begin{array}{l}\text { Mild side effects } \\
\text { like gastrointestinal } \\
\text { complaints, fatigue and } \\
\text { altered taste }\end{array}$ \\
\hline Diazepam & $\begin{array}{l}\text { Causes inhibition throughout the } \\
\text { central nervous system, including } \\
\text { activity in the vestibular nerve and } \\
\text { vestibular nuclei }\end{array}$ & $\begin{array}{l}5 \mathrm{mg} / 6-8 \\
\text { hours }\end{array}$ & $\begin{array}{l}\text { Anxiety and } \\
\text { vertigo }\end{array}$ & $\begin{array}{l}\text { Drowsiness, } \\
\text { dizziness and } \\
\text { respiratory depression }\end{array}$ \\
\hline
\end{tabular}

\section{Cinnarizine}

It has a vital role in the treatment of vertigo by blocking the entry of calcium into the plasma membranes particularly after adrenergic stimulation. The primary action of this drug is acting as a labyrinthine suppressants or labyrinthine sedative. ${ }^{16}$ Cinnarizine has also antihistaminic and anticholinergic effects. The labyrinthine sedative effect is achieved for prolonged period of 6 to 8 weeks. The side effects of cinnarizine include drowsiness and also weight gain. Gastrointestinal disturbances and depression may also find but less frequently. Calcium channel blockers such as cinnarizine are not usually recommended in pregnancy. ${ }^{17}$

\section{Combination of cinnarizine and dimenhydrinate}

The combination of the cinnarizine and dimenhydrinate is very well tolerated and effective for treatment of the acute attack of the vertigo. ${ }^{18}$ However, combination drugs of the same class of drugs is not useful. It has also found long term use of antivertigo drugs and or tranquilizers is counterproductive for compensation of the vestibular symptoms. This combination drugs should be considered in patients with acute vertigo and stopped once the symptoms subside. The combination drug of cinnarizine and dimenhydrinate has no effect on the memory. One study showed that dimenhydrinate adversely affects to psychomotor function, but the single dose of the cinnarizine is not related with any negative effects on the performance. ${ }^{19}$ Cinnarizine is also associated with drowsiness so hampering the performance like driving. It is also not advised for use in pregnancy.

\section{Histaminergic medications}

This group of drugs includes beta-histine which is an analogue of the L-histidine, an immediate precursor of the histamine. This medication act on the basis of the vasodilatory effect which improve the blood flow to the vestibular system. ${ }^{20}$ Beta-histine has a complex effect on the receptor of the histamines such as both a partial H1 post-synaptic agonist causing vasodilation and $\mathrm{H} 3$ presynaptic antagonist leading to increased histamine secretion and facilitation of the histaminergic neurotransmission, so improves the neuronal electrical activity at the vestibular nuclei. ${ }^{21}$

\section{Beta-histine}

Beta-histine is considered as one of the chosen antivertigo used globally. Beta-histine dihydrochloride is a histamine analogue and partial agonist at $\mathrm{H} 1$ receptors and potent antagonist to $\mathrm{H} 3$ receptor. It acts as the histamine agonists. Beta-histine facilitates the vestibular compensation. The efficacy of the beta-histine is due its action on the receptors of the histamine. ${ }^{22}$ It is used in the treatment of the vertigo due to different etiologies. The therapeutic effect of the beta-histine depends on the doses and duration of the drug. ${ }^{23}$ It is also moderately effective in controlling the symptoms in Meniere's disease. ${ }^{24}$ The effectiveness of this is often visible after taking the drugs for 2 to 3 months. Several human and animal studies 
documented that beta-histine enhances the blood flow to the labyrinth and brain by its action on $\mathrm{H} 1$ receptors. ${ }^{24}$

\section{Prochlorperazine}

Prochlorperazine is used since long for treatment of the vertigo. One study documented that prochlorperazine was superior to cinnarizine for controlling vertigo in Indian population. ${ }^{25}$ Prochlorperazine has anticholinergic and dopaminergic effects and so relieves the severe spinning sensation and also associated vegetative symptoms such as nausea and vomiting. ${ }^{26}$ It is a safe and effective drug for treating the dizziness along with nausea and vomiting. Prochlorperazine is usually prescribed for short terms like up to one week for managing acute attacks and should be checked for extra-pyramidal symptoms.

\section{Dopaminergic antagonists}

These drugs usually used to control nausea in vertigo patients. There are some antipsychotic drugs namely phenothiazine derivatives and butyrophenones are common in this condition. Narcoleptics act as antiemetic effect by blocking the dopaminergic receptors at the postrema of the brainstem. These medications decrease the neurovegetative symptoms which commonly parallel vertigo and so improve the psycho affective presentations associated with vertigo. These drugs do not exert direct dopaminergic vestibular effects but not associated with anticholinergic and antihistaminic properties that explain a vestibular sedative activity. ${ }^{27}$ Metoclopramide is a dopaminergic antagonist as well as serotonergic antagonist increase the gastric emptying and also has a central antiemetic effect by acting on the chemoreceptor trigger zone at the medulla oblongata. The side effects of these medications are dry mouth, sedation and extrapyramidal symptoms.

There are some newer 5-HT3 receptor antagonists such as ondansetron, tropisetron and granisetron block the afferent vagal impulses and vomiting center at the medulla oblongata. These are used as drug of choice in cancer chemotherapy, radiotherapy and surgery or anesthesia induced nausea and vomiting. These drugs are rarely helpful to control the nausea and vomiting in vertigo. ${ }^{28}$ Few antihistamines such as promethazine also block dopamine receptors and so helpful in vertigo. ${ }^{29}$

\section{Benzodiazepines}

The benzodiazepines (BZDs) are vestibular suppressants by acting through the GABA ergic system. GABA is a neurotransmitter which inhibits vestibular system. BZDs activate the effect of GABA in central nervous system and so helpful in relieving vertigo along with anxiety and panic disorders. ${ }^{30}$ It has also muscle relaxant property and cause anterograde amnesia. The common BZDs used in medical practice are diazepam, lorazepam, clonazepam and alprazolam. ${ }^{31}$

\section{Calcium channel blockers}

The calcium channel blockers are useful to control vertigo. These drugs cause vestibular suppression by blocking the calcium channels of the vestibular hair cells. Although cinnarizine is an antihistamine, also block the calcium channel. The calcium channel blockers block the inflow of the calcium from endolymph to the cells at the crista ampularis, which is needed for activating the action potential which is propagated centrally. ${ }^{32}$ Cinnarizine is very effective for controlling the peripheral vertigo. A fluorinated derivative of cinnarizine which is flunarizine acts as potent and long acting labyrinthine suppressant. These drugs prevent from motion sickness and control vertigo by suppressing peripheral vestibular system.

\section{Anticonvulsants}

Although no extensive study done on anticonvulsants for acting on vertigo but the drugs such as gabapentin, carbamazepine and oxcarbazepine are helpful in the treatment of the vertigo. These are useful in the treatment of nystagmus. Baclofen is a GABA agonist, has been tried for treatment of the vertigo by lowering the asymmetric vestibular stimulation, but no human trial done for this. ${ }^{33}$

\section{Diuretics}

Diuretics with low salt diet are advised in Meniere's disease. Diuretic especially potassium sparing is useful for controlling the recurrence of the vertigo. Acetazolamide is a carbonic anhydrase inhibitor and used for Meniere's disease in some countries. A combination of triamterene and hydrochlorothiazide is widely used in United States of America. This is a potassium sparing diuretic and the side effects are hypokalemia and impotence. So, potassium rich diet or potassium supplementation should be given to the patients along with potassium sparing diuretic. Current study shows that diuretic decrease the volume and pressure of the endolymphatic fluid and also suddenly lowers the blood pressure. This may lead to exaggeration of the vasomotor response leading to the ischemia to the labyrinth so can cause permanent damage to the inner ear. So, role of the diuretics in Meniere's disease is often questionable. ${ }^{34}$

\section{Steroids}

Methylprednisolone is a useful drug for improving vestibular function in patients of vestibular neuronitis by its anti-inflammatory activity. Meniere's disease is thought to be as autoimmune disorders so, the role of the steroids has an important role. It lowers the inflammatory edema of the endolymphatic sac in Meniere's disease. In some cases, corticosteroids also improve the compensation of the vertigo. A gradual tapered dose of steroids can improve the hearing and vertigo in Meniere's disease. Intra-tympanic injection of dexamethasone via tympanostomy tube gives higher concentration and better 
outcome with less systemic side effects in Meniere's disease. One study shows intra-tympanic injection of 16 $\mathrm{mg}$ methylprednisolone and $16 \mathrm{mg}$ IV dexamethasone for three days followed by dexamethasone orally improve the hearing in $35.4 \%$ cases and vertigo control in $63.5 \% .{ }^{35} \mathrm{In}$ case of acute Cogan syndrome, high dose of methylprednisolone at the beginning and tapered gradually. ${ }^{36}$ Prolonged use of steroids may precipitates peptic ulcer, hypertension, diabetes mellitus, steroid induced depression and fixed drug eruption.

\section{Antimicrobial agents}

Transtympanic injection of gentamycin has been seen to reduce the episodic attacks of the vertigo in Meniere's disease. It acts by directly damaging the type-I hair cells of the inner ear. Hearing loss is also anticipated to occur after this injection. ${ }^{37}$

\section{Ginko biloba}

Ginko biloba is an herbal medicine, claimed to enhance the cognitive function. It enhances the microcirculation and also has anti-oxidant properties. One study documented an equal efficacy of the beta-histine and ginko biloba in treatment of the vertigo. ${ }^{38}$ The usual dose of the Ginko biloba is $40 \mathrm{mg}$ thrice daily. It is also using as cerebral activator in disease with cerebral impairment. A major adversity with its use is adverse drug interaction due to its anti-platelet and anticoagulant activity as it has platelet activating factor antagonist effect. ${ }^{39}$

\section{Nootropic drugs}

Piracetam is a nootropic drug which is a cyclic derivative of GABA. It relieves vertiginous symptom after a head injury or central vertigo particularly in case of vertebrobasilar insufficiency. It helps to reduce frequency of the vertigo but not the severity of the vertigo in case of recurrent or chronic vertigo. ${ }^{40}$

\section{Miscellaneous agents}

Acetyl leucine act as a precursor of a peptidic neurotransmitter cause activation of the vestibular afferents. It also has anti-calcium nature in neurotransmission. Intravenous and oral forms of acetyl leucine are available. It was marketed in France for treatment of vertigo. ${ }^{41}$

\section{Drugs for psychogenic vertigo}

Psychotropic agents like benzodiazepines (anxiolytics) or antidepressants like tricyclic antidepressants (TCAs) can be prescribed for psychogenic vertigo. Although the drugs like TCAs are effective in panic and generalized anxiety disorders; these are highly anti-cholinergic and antihistaminic. In psychogenic vertigo, selective serotonin reuptake inhibitors (SSRIs) like fluoxetine, paroxetine, sertraline and citalopram with conventional doses can be given for twenty weeks which give some positive results. ${ }^{42}$ SSRIs are becoming more popular as first line drugs for treating psychogenic vertigo with primary anxiety disorders.

\section{CONCLUSION}

Vertigo is a symptom of varying causes. It often gives challenge for complete cure or long-term remission. In clinical practice, common etiologies for vertigo are benign paroxysmal positional vertigo, Meniere's disease, vestibular neuritis, migrainous vertigo and vestibular ototoxicity. The treatment depends on the getting correct diagnosis. Pharmacotherapy plays a vital role for cure of the vertigo. Vestibular suppressant drugs are the mainstay of the managing acute attacks of the vertigo. However, the treatment of the patient with vertigo of unknown etiology is empiric. A methodical and organized approach is required for getting effective result and getting maximum patient satisfaction.

\section{Funding: No funding sources \\ Conflict of interest: None declared \\ Ethical approval: Not required}

\section{REFERENCES}

1. Young AS, Lechner C, Bradshaw AP, Dougall MHG, Black DA, Halmagyi GM, et al. Capturing acute vertigo: a vestibular event monitor. Neurology. 2019;92(24):2743-53.

2. Zwergal A, Strupp M, Brandt T. Advances in pharmacotherapy of vestibular and ocular motor disorders. Expert Opinion Pharmaco. 2019;20(10):1267-76.

3. Zatonski T, Temporale H, Holanowska J, Krecicki T. Current Views on Treatment of Vertigo and Dizziness. J Med Diagn Meth. 2014;2:150.

4. Swain SK, Baliarsingh D, Sahu MC. Vertigo among elderly people: Our experiences at a tertiary care teaching hospital of eastern India. Annals Indian Academy Otorhinolaryng Head Neck Surg. 2018;2(1):5.

5. Swain SK, Anand N, Mishra S. Vertigo among elderly people: current opinion. J Med Society. 2019;33(1):1.

6. Swain SK, Behera IC, Das A, Sahu MC. Prevalence of Benign Paroxysmal Positional Vertigo: our experiences at a tertiary care hospital of India. Egyptian J ENT Allied Sci. 2018;19(3):87-92.

7. Swain SK, Sahu MC, Samal R, Padhy RN. Incidence of hearing loss, tinnitus and vertigo among diabetes patients. Siriraj Med J. 2014;66:179-84.

8. Xue H, Chong Y, Jiang ZD, Liu ZL, Ding L, Yang SL, et al. Etiological analysis on patients with vertigo or dizziness. Zhonghua Yi Xue Za Zhi. 2018;98(16):1227-30.

9. Nerveen JV, Pompeiano O, Collewign $\mathrm{H}$. Depression of the vestibule-ocular reflex and 
optokinetic responses in intra floccular microinjection of GABA-A and GABA-B agonists in rabbit. Arch Ital Biol. 1989;127:243-63.

10. Gilchrist D, Smith P, Darlington C. ACTH (4-10) accelerates ocular motor recovery in guinea pig's medical vestibular neurons. Eur $\mathrm{J}$ Neurosci. 1995; 7:555-62.

11. Daroff R. Dizziness, Vertigo. In Fauci AS, Kasper DL, Longo DL, Braunwald E, Hauser SL, Jameson JL (Eds). Principles of Internal Medicine. New York, USA: McGraw Hill; 298; 144.

12. Takeda N, Mashahiro M, Hasegawa S, Kubo T, Matsunaga T. Neurochemical mechanisms of motion sickness. Am J Otolaryngol. 1989;10:351-9.

13. Bisht M, Bist SS. An update of pharmacotherapy of vertigo. J Chem Pharm Res. 2010;2(3):381-6.

14. Cohen B, Jong DJ. Meclizine and placebo in treating vertigo of vestibular origin, Relative efficacy a double-blind study. Arch Neurol. 1972;27:129-35.

15. Weinstein SE, Stern RM. Comparison of Marezine and Dramamine in preventing symptoms of motion sickness. Aviation Space Environmental Med. 1997;68:890-4.

16. Towse G. Cinnarizine a labyrinthine sedative. J Laryngol Otol. 1980;94(9):1009-15.

17. Berisavac II, Pavlovic AM, Trajkovic JJ, Sternic NM, Bumbasirevic LG. Drug treatment of vertigo in neurological disorders. Neurol India. 2015;63(6):933-9.

18. Scholtz AW, Steindl R, Burchardi N, BognarSteinberg I, Baumann W. Comparison of the therapeutic efficacy of a fixed low-dose combination of cinnarizine and dimenhydrinate with beta-histine in vestibular neuritis: a randomized, double-blind, non-inferiority study. Clin Drug Investig. 2012;32(6):387-99.

19. Gordon CR, Gonen A, Nachum Z, Doweck I, Spitzer O, Shupak A. The effects of dimenhydrinate, cinnarizine and transdermal scopolamine on performance. J Psychopharmacol. 2001;15(3):16772.

20. Halmagyi GM. Vertigo and vestibular disorders In: Eadie J, (Ed). Drug therapy in neurology. Edinburgh: Churchill Livingston; 1992: 383.

21. Lacour M, Sterkers O. Histamine and beta-histine in the treatment of vertigo: Elucidation of mechanism of action. CNS Drugs. 2001;15:853-70.

22. Kameshwaran M, Sarda K. Therapeutic interventions in vertigo management. Int $\mathrm{J}$ Otorhinolaryngol Head Neck Surg. 2017;3(4):77785.

23. Lacour M. Beta-histine treatment in managing vertigo and improving vestibular compensation: clarification. J Vestib Res. 2013;23(3):139-51.

24. Bisht M, Bist SS. An update on pharmacotherapy of vertigo. J Chem Pharm Res. 2010;2(3):381-6.

25. Singh AK, Chaturvedi VN. Prochlorperazine versus cinnarizine in cases of vertigo. Indian J Otolaryngol Head Neck Surg. 1998;50(4):392-7.
26. Biswas A. Vertigo-What is new in it from the general physician's perspective. Med Update. 2012;22:586-91.

27. Rascol O, Hain TC, Brefel C, Benazet M, Clanet M, Montastruc JL. Antivertigo medications and drug induced vertigo. Drugs. 1995: 777-91.

28. Wilde MI, Markham A. Ondensetron: a review of its pharmacology and preliminary clinical findings in novel applications. Drugs. 1996;52:773-94.

29. Bosch D, Schmid S. Activation of muscarinic cholinergic receptors inhibits giant neurons in the caudal pontine reticular nucleus. Eur J Neurosci. 2006;24:1967-75.

30. Takeno K, Shimogori H, Takemoto T, Tanaka K, Mikuriya T, Orita H, et al. The systemic application of diazepam facilitates the reaquisition of a wellbalanced vestibular function in a unilateral vestibular reinput model with intracochlear tetrodotoxin infusion using an osmotic pump. Brain Res. 2006;1096:113-9.

31. Hain TC, Uddin M. Pharmacological treatment of vertigo. CNS Drugs. 2003;17:85-100.

32. Prigioni I, Masetto S, Russo G, Taglietti V. Calcium current in solitary hair cells isolated from frog crista ampullaris. J Vestib Res. 1992;2(1):31-9.

33. Cohen B, Helwig D, Raphan T. Baclofen and velocity storage:a model of the effects of the drug on the vestibule-ocular reflex in the Rhesus monkey. J Physiol. 1987;393:703-26.

34. Pirodda A, Ferri GG, Raimondi MC, Borghi C. Diuretics in Meniere disease: a therapy or a potential cause of harm. Med Hypotheses. 2011;77(5):869-71.

35. Shea JJ. The role of dexamethasone or streptomycin perfusion TN the treatment of Meniere's disease. Otolaryngologic Clin North Am. 1997;30:1051-9.

36. Strupp M, Dieterich M, Brandt T. The Treatment and Natural Course of Peripheral and Central Vertigo. Deutsches Arzteblatt Int. 2013;110 (2930):505-16.

37. Casani AP, Piaggi P, Cerchiai N, Seccia V, Franceschini SS, Dallan I. Intra-tympanic treatment of intractable unilateral Meniere disease: gentamicin or dexamethasone? a randomized controlled trial. Otolaryngol Head Neck Surg. 2012;146(3):430-7.

38. Cesarani A, Meloni F, Alpini D, Barozzi S, Verderio L, Boscani PF. Ginko biloba (EGb 761) in the treatment of equilibrium disorders. Adv Ther. 1998;15:291-304.

39. Swain SK, Behera IC, Sahu MC. Role of Ginko biloba for controlling residual dizziness after successful treatment of benign paroxysmal positional vertigo: our experiences at a tertiary care teaching hospital of Eastern India. Int $\mathrm{J}$ Health Allied Sci. 2018;7:196-200.

40. Oosterveld WJ. The effectiveness of piracetam in vertigo. Pharmacopsychiatry. 1999;32(1):54-60.

41. Freyss G, Vitte E. Strategie, diagnostic therapeutique devant un sujet de perte soudaine de 
la function vestibulaire. Cah Otolaryngol. 1990;15:569-82.

42. Dieterich M. Dizziness. Neurologist. 2004;10(3):154-64.

Cite this article as: Swain SK. Pharmacotherapy for vertigo: a current perspective. Int J Otorhinolaryngol Head Neck Surg 2020;6:1400-6. 